\title{
APPLICATION FOR SOURCE PARAMETERS CALCULATIONS AS INPUT FOR STATIC STRESS CHANGES STUDIES
}

\author{
Paradisopoulou P. M. ${ }^{1}$, Papadimitriou E. E. ${ }^{1}$, Karakostas V. G. ${ }^{1}$, and \\ Kilias A. ${ }^{2}$ \\ ${ }^{1}$ Department of Geophysics, School of Geology, Aristotle University of Thessaloniki, GR54124, \\ Thessaloniki,Greece,popi.paradis@gmail.com,ritsa@geo.auth.gr,vkarak@geo.auth.gr, \\ ${ }^{2}$ Department of Geology, School of Geology, Aristotle University of Thessaloniki, GR54124, \\ Thessaloniki,Greece,kilias@geo.auth.gr
}

\begin{abstract}
The study of static Coulomb Stress changes requires initially the collection of information on the major active faults in a study area concerning their geometry and kinematic properties and then a series of complex calculation for stress changes that are associated with both coseismic displacements of the stronger events and the tectonic loading on these major faults. The Coulomb Stress Application has been developed as a tool to provide a user-friendly way of entering the necessary data and an efficient way to perform the complex calculations procedure. More specifically the aim of the application is a) the collection of data (catalogues of earthquakes, fault parameters) in a relational database, b) the calculation of earthquake source parameters such as the length and the width of the causative fault, and the coseismic slip by using available scaling laws, and finally, c) the execution of all the necessary programs and scripts (e.g. dis3dop.exe, GMT package) to get a map of static stress changes for an area. Coulomb Stress application provides a way to store these data for a study area and it is a method to perform a series of calculations by plotting a series of maps and examine the results for a number of cases.
\end{abstract}

Key words: Database population, execution, fault geometry.

\section{Пврі́іпчи}

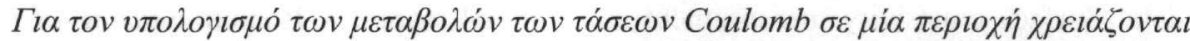

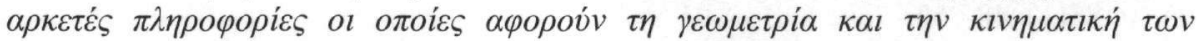

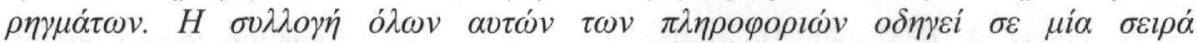

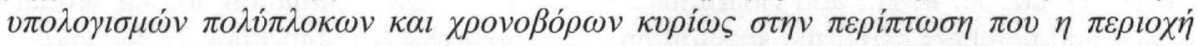

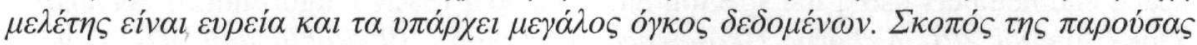

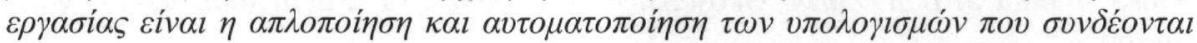

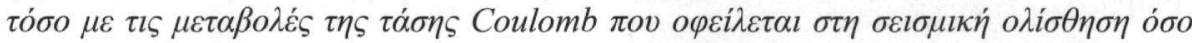

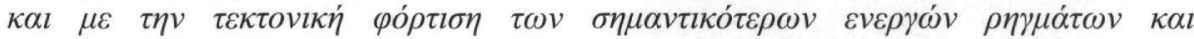

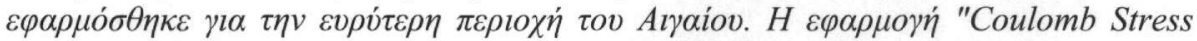

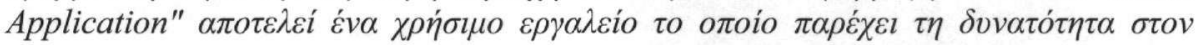

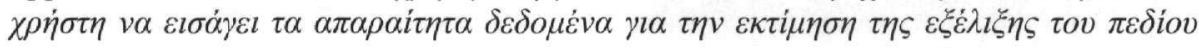




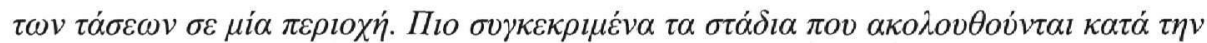

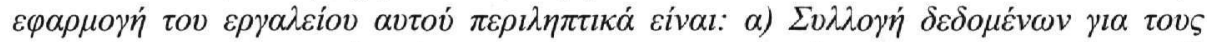

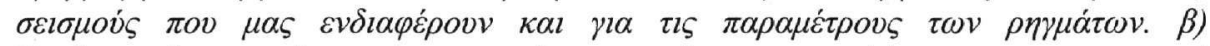

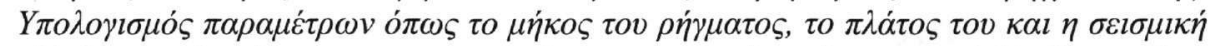

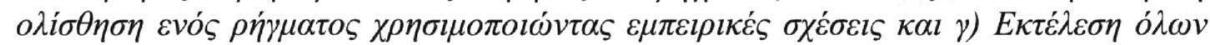

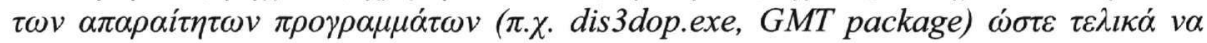

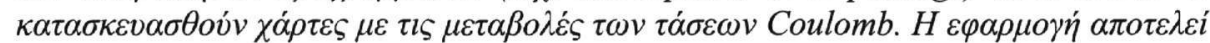

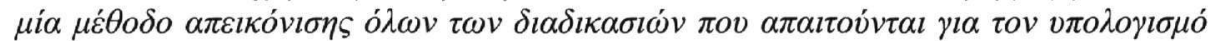

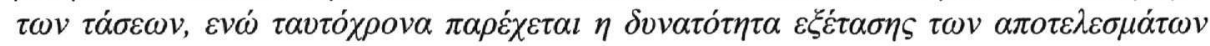

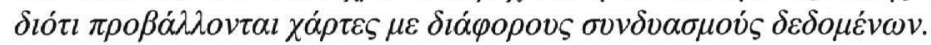

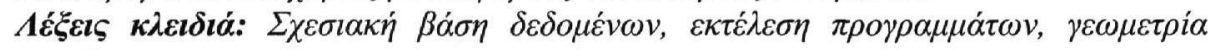
$\rho \eta \gamma \mu \alpha \dot{\alpha} \omega \nu$.

\section{Introduction}

Strong earthquakes appeared to cluster on both time and space scales. Such observations have led several authors in the last decade to highlight the importance of fault interactions on the basis of physical models. Considerable research has been performed on earthquake triggering or delay due to changes in stress and this topic has been extensively discussed (e. g. Harris 1998 and references therein). The points faced by researchers concern the possible triggering of subsequent earthquakes by earthquake-induced static or dynamic stress changes. The advantage of using changes in stress is that oftentimes, absolute values of stress are not known but stress change values can be calculated fairly readily from information about the geometry and slip direction of an earthquake rupture. The Coulomb failure stress changes caused by main shock rupture effectively explain the aftershock distributions for the earthquakes studied, with some of the more distant events apparently being triggered by stress changes as low as 0.1 bar (Reasenberg and Simpson 1992). For example, the next strong earthquake on portions of the San Andreas Fault is calculated to have advanced about a decade in the cycle of great earthquakes by the 1992 Landers sequence of earthquakes (Jaumé and Sykes 1992). Not only do aftershocks appear to be triggered by such stress changes, but moderate seismicity prior to the Landers earthquake increased the potential for failure along most of the future Landers rupture zone, perhaps controlling the location of the later rupture (King et al. 1994).

The methodology applied by authors of the present paper for static stress changes association with consequent strong earthquake occurrence, as well as modification in the seismicity rate in an area (e.g. Papadimitriou and Sykes 2001, Papadimitriou et al. 2004) is the one introduced by Deng and Sykes (1997). According to this methodology the stress is considered to be a tensor quantity that varies both in time and space, with the Earth approximated as a homogeneous half space. Stress changes are associated with the coseismic displacements of the strongest events (e.g. $\mathrm{M} \geq 6.5$ ) and the tectonic loading on the major faults. In order to estimate the interseismic stress accumulated around a major fault in an area, the term of "virtual negative displacements" has been introduced. These virtual dislocations are imposed on the faults with sense of slip opposite to the observed slip during the earthquake occurrence, and are incremented in time according to the long-term rate of the fault. This is equivalent to constant positive slip extending from the bottom of the seismogenic layer to infinite depth. Hence, tectonically induced stress builds up in the vicinity of faults during interseismic periods. All computed interseismic stress accumulation is associated with the deformation caused by the time-depended virtual displacement on major faults extending to the depth at witch earthquakes and brittle behaviour cease $(\sim 15 \mathrm{~km})$. Stress build up is released wholly or in part during the next strong earthquake, with real displacements on given fault segments that are considered positive in the model. Changes in stress associated with strong earthquakes are calculated for coseismic displacements on each ruptured fault segment and by adding the changes in the components of the stress tensor together as they occur in time. 
Stress changes that concern earthquake displacements require the existence of a dislocation model. It refers to a planar orthogonal fault surface, $\Sigma$, with a finite length perpendicular to earth's surface and a finite width and embedded in an elastic half space. Displacement across a surface $\Sigma$ (Steketee 1958), is determined from:

\section{Equation 1 - Displacement across a surface $\Sigma$}

$$
u_{\kappa}=\frac{U_{i}}{8 \pi \mu} \iint_{\Sigma} w_{i j}^{k} u_{j} d \Sigma
$$

where: $\mu$ is the shear modulus, $\mathrm{u}_{\mathrm{j}}$ are the direction cosines of the normal to the surface, $\mathrm{U}_{\mathrm{i}}$ is the $i_{\text {th }}$ component of $U$ and $w^{k}{ }_{i j}$ are the six sets of Green ' $s$ functions.

The elastic stress $\mathrm{s}_{\mathrm{ij}}$ derived from strain $\mathrm{e}_{\mathrm{ij}}$ using Hooke's law, for an isotropic medium is given by:

\section{Equation 2 - Elastic stress}

$$
s_{i j}=\frac{2 \mu \nu}{1-2 v} \delta_{i \xi} e_{k k}+2 \mu e_{i j}
$$

where $\mu$ is the shear modulus, $v$ is the Poisson's ratio and $\delta_{\mathrm{ij}}$ is the Kronecker delta.

Earthquakes occur when the stress exceeds the strength of the fault. The closeness to failure was quantified by using the change in Coulomb failure function ( $\triangle \mathrm{CFF}$ ) (modified from Scholz 1990). It depends on both changes in shear stress, $\Delta \tau$, and normal stress, $\Delta \sigma$ :

\section{Equation 3 - Changes of Coulomb Failure Function}

$\Delta \mathrm{CFF}=\Delta \tau+\mu^{\prime} \Delta \sigma$ where $\mu^{\prime}=\mu(1-\mathrm{B})$

where $\mu^{\prime}$ : the apparent coefficient of friction which is given in equation 3 where, B is the Skempton's coefficient and varies between 0 and 1 . The parameter $\mu^{\prime}$ includes the effects of pore fluids and material properties of the fault zone, $\Delta \tau$ : is the change in shear stress, $\Delta \sigma$ : is the change in normal stress. $\Delta \sigma, \Delta \tau$ : are calculated for a fault plane at the observing (field) point

For increasing shear stress in the direction of relative slip on the observing fault $\Delta \tau$ is positive. $\Delta \sigma$ is positive for tensional normal stress. When compressional normal stress on a fault plane decreases, the static friction across the fault plane also decreases. Both positive $\Delta \tau$ and $\Delta \sigma$ move a fault toward failure. Negative $\Delta \tau$ and $\Delta \sigma$ move it away from failure. A positive value of $\Delta C F F$ for a particular fault denotes movement of that fault toward failure (that is, likelihood that it will rupture in an earthquake is increased). In places where $\triangle \mathrm{CFF}$ is negative the fault is assumed to have relaxed and turned into a stress shadow zone needing a long time to recover.

Earthquakes nucleate on active fault surfaces often approximated with rectangles dipping within the brittle layer of the earth's crust. Fault planes are adequately described with the use of geometrical parameters such as the length and the width of the fault zone and the fault plane solution. To calculate rupture parameters that are necessary for the model application we use empirical relationships when field observations or relevant information from previous investigations are not available. Wells and Copersmith (1994) and Papazachos et al. (2004) collected worldwide data and proposed scaling laws for different seismotectonic environments, by which the fault dimensions (fault length, L, fault width, w, and fault surface, S) as well as coseismic displacement, $\mathrm{u}$, can be calculated as a function of the earthquake magnitude, which in our case is either moment magnitude or equivalent moment magnitude. The equations proposed for fault dimensions and coseismic slip, are given by the following relationships:

- Wells and Coppersmith (1994) equations: 
Equation 4 - Fault length (L), fault width (w) and coseimic slip (u), for strike slip faults

$\log L=0.74 M-3.55$

$\log w=0.27 M-0.76$

$\log u=1.03 M-7.03$

Equation 5 - Fault length (L), fault width (w) and coseimic slip (u), for normal faults

$\log L=0.5 M-2.1$

$\log w=0.35 M-1.14$

$\log u=0.89 M-5.9$

Equation 6 - Fault length (L), fault width (w) and coseimic slip (u), for thrust faults

$\log L=0.63 M-2.86$

$\log w=0.41 M-1.61$

$\log u=0.29 M-1.84$

Equation 7 - Fault length (L), fault width (w) and coseimic slip (u), for subduction earthquakes

$\log L=0.69 M-3.22$

$\log w=0.32 M-1.01$

$\log u=0.82 M-5.46$

- Papazachos et al. (2004) equations

Equation 8 - Fault length (L), fault width (w) and coseimic slip (u), for dip slip crustal faults

$\log L=0.5 M-1.86$

$\log w=0.28 M-0.7$

$\log u=0.72 M-2.82$

Equation 9 - Fault length (L), fault width (w) and coseimic slip (u), for strike slip faults

$\log L=0.59 M-2.30$

$\log w=0.23 M-0.49$

$\log u=0.68 M-2.59$

Equation 10 - Fault length (L), fault width (w) and coseimic slip (u), for subduction earthquakes

$$
\begin{aligned}
& \log L=0.55 M-2.19 \\
& \log w=0.31 M-0.63 \\
& \log u=0.64 M-2.78
\end{aligned}
$$

The methodology described above is applied in the broader Aegean territory with the aim to examine the evolution of stress field and its association with seismicity. For this purpose, the coseismic displacements of earthquakes with $\mathrm{M} \geq 6.5$ that occurred since 1900 until present along with the tectonic loading on the major faults in the study area are taken into account. At each stage of the evolutionary model possible triggering of the strong events is inspected. In this way it can be revealed if the history of cumulative changes in stress can explain the spatial and temporal seismicity patterns. 
Relevant investigation about automatization of Coulomb stress calculation has been conducted by Toda et al. (2007). This software is a scientific tool and it includes all the necessary calculations and parameters used for Coulomb stress changes in matlab environment. The user can add active fault traces, coastlines and earthquakes from online catalogues or Coulomb-bundled database file as well as can create graphic files and plot stress changes on faults in their individual rake direction or on specified rakes. This software also uses files which supply all geometrical features needed to use the database faults as sources or receivers, slip rate of faults and rake.

When Coulomb stress changes are calculated, taking into account both large number of earthquakes and the faults which the tectonic loading is considered is quite consuming in terms of time and effort. The Coulomb Stress Application was developed as a tool that provides an automatic and efficient procedure to the researcher who studies the source parameters calculation and static stress changes in each stage of the stress evolutionary model. We form a related database which consists of all the parameters that are needed as an input to the dis3d program (Erickson 1986). The application is designed for two main purposes. The first one concerns the calculation of fault parameters (dimensions and coseismic slip) of each earthquake included in the stress evolutionary model, while the second one concerns the calculation of the accumulated stress changes. Information that is needed further for the model application, and is added to the database, concerns the long-term slip rates on the major regional faults as well as the available and reliably determined fault plane solutions. An additional potential of the program is that all the geometrical parameters of the faults are calculated directly using empirical relationships (in our case from Wells and Coppersmith 1994, Papazachos et al. 2004). In addition, the application uses GMT package (Wessel and Smith 1998) to plot maps either with the regional morphology or snapshots of the stress field evolution.

\section{Application architecture and design}

The Coulomb Stress Application was developed under Windows Operating System, using Microsoft Visual C\# programming language and Microsoft Access. The application was designed based on the 3-tier architecture pattern (data layer, calculation layer and user interface layer). The three layers of which the application is consisted of are the following:

\subsection{Database layer}

All the data, which are used by the application, are being stored in tables of a relational database developed in Microsoft Access. In brief the basic tables of the database are the following:

- Information on the strong earthquakes

- Source parameters of the faults that are associated with coseismic displacements

- Source parameters of the major faults on which the tectonic loading is considered

- Scaling laws used for the calculations of source parameters (fault length, fault width, coseismic slip)

\subsection{Calculation layer}

The calculation layer of the application is a collection of various executables written in FORTRAN programming language and scripts based on the GMT (Generic Map Tools) package (Wessel and Smith 1998). GMT is an open source collection of about sixty tools for manipulating geographic and Cartesian data sets (including gridding, projecting etc.) and producing postscript file illustrations ranging for a simple plot to a complicate map (artificially illuminated surfaces, 3D perspective views). GMT also supports projections, transformations and data such as coastlines, rivers, boundaries, epicentres, focal mechanisms, faults etc. For the proper execution of the calculation layer of the Coulomb Stress application it is mandatory that the GMT package be installed in computer where the application is executed. 
The programs used for the calculations are the following:

- Dis3d.exe (Erickson 1986). This is a three-dimensional program that calculates the displacements, strain and stresses due to strike slip or dip slip motion on any number of rectangular dislocation planes located in linear elastic half-space. The program's input routines allow the user to specify individual observational points, grids of observation points in any plane of half space and permit the calculation of the elastic fields with respect to any reference structure specified by the user. Di3d can also calculate changes in line lengths between any two observation points and changes in angles between any three observation points especially in case of applications involving fault monitoring with geodetic measurements. The source code of the program was modified in order to run for a wider grid area.

- Title.exe and cstress.exe. These programs are used for the modification and the transformation of the local coordinates in geographical ones, of the Dis $3 \mathrm{~d}$ output. They have been developed by collaborative work of the one of the authors of this study (V. Karakostas and X.-W. Du). The output file from these programs are the inputs of a GMT *.bat file, for plotting the resulted calculations.

\subsection{User interface layer}

The User Interface layer has been developed using the Multi Document Interface (MDI) model. Using the user interface layer the user has full control over the contents of the database (insert new records, modify and delete existing records). From this layer the user of application can spawn the calculation layer for a specific dataset and finally view the results (data files or maps).

For the better understanding the application and the way of its function is depicted in the diagram below (Fig. 1).

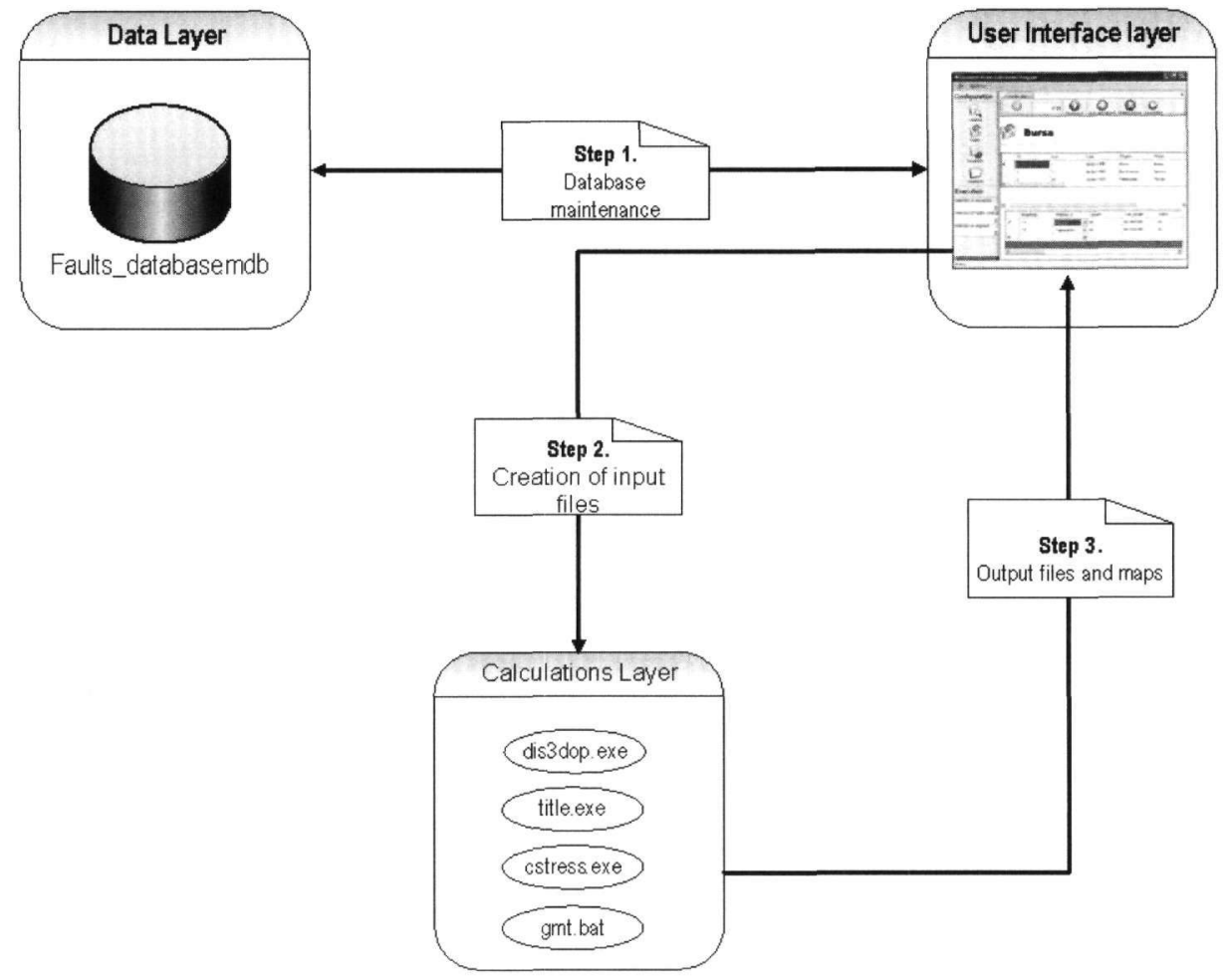

Figure 1 - Application architecture diagram 


\section{Functionality of Coulomb Stress Application}

The functionality of the application can be divided in three basic categories: Database population, execution of calculations and plotting of the results.

\subsection{Database population}

\subsubsection{Catalogues}

In the catalogues table the user provides an identification of earthquakes groups in a study area (i.e earthquakes in Greece, in China, in Turkey etc.) and has the capability to add new record or delete a record (Fig. 2). Example: If we type Name of catalog: Turkey, and then save data this catalogue will appear as a selection to later calculations.

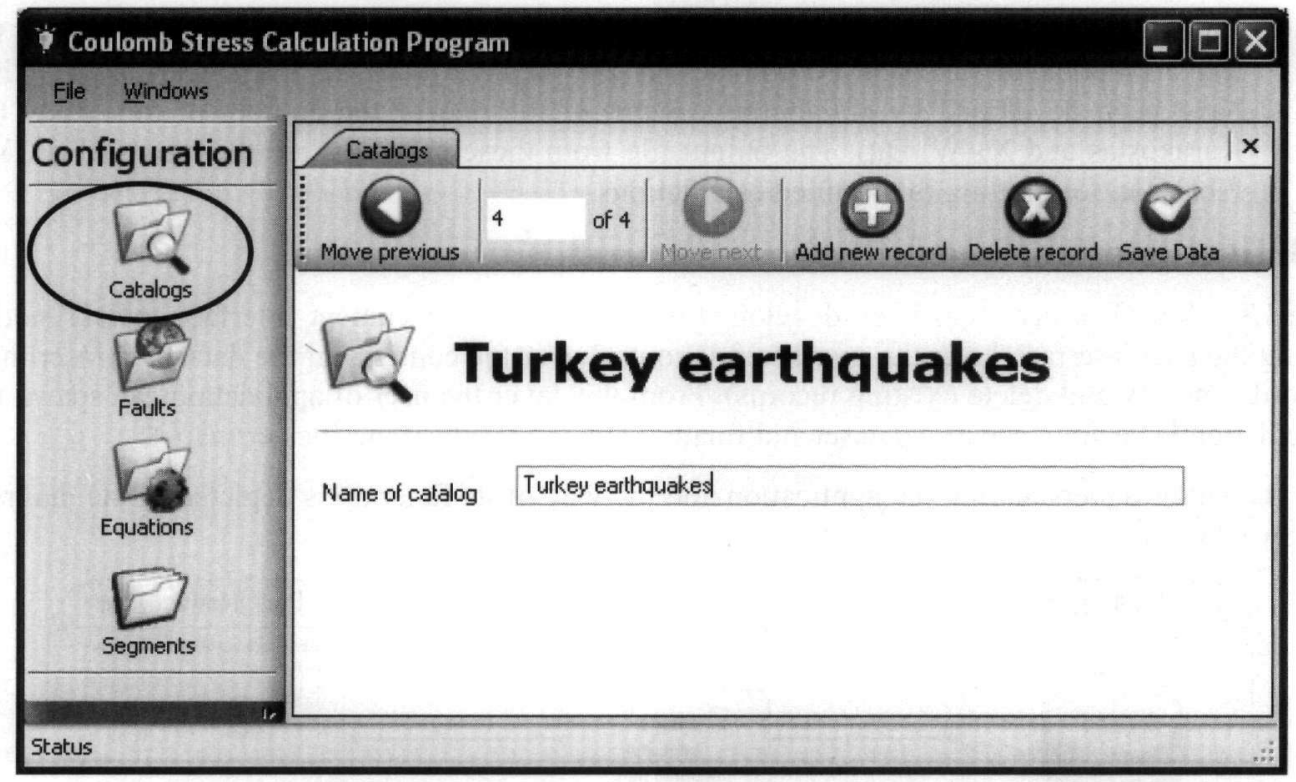

Figure 2-An illustration of the applications category: catalogues

\subsubsection{Earthquakes and Faults associated with coseismic displacement}

The source parameters of each strong earthquake and the associated active fault that are used for the calculation of coseismic displacements are entered in the database. For each case the user provides the following information:

\section{- Strong Earthquakes:}

- Date (day/mm/yyyy) and region of occurrence of the event

- Epicentre of the earthquake (Latitude and Longitude in degrees)

- Focal depth

- The earthquake magnitude (moment magnitude or equivalent moment magnitude)

- Focal mechanism of the earthquake (strike, dip, rake)

- Seismic moment $\mathrm{M}_{\mathrm{o}}$ (in dyn.cm): for $\mathrm{M}_{\mathrm{o}}$ previous studies are taken into account.

When the seismic moment $\left(\mathrm{M}_{0}\right)$ of an earthquake was known the coseismic displacement was computed from the following equation: 


\section{Equation 10 - Scalar seismic moment (Aki, 1966):}

$$
M_{0}=\mu u w L
$$

Where: $\mu$ is equal to $3.3 \cdot 10^{11} \mathrm{dyn} / \mathrm{cm}^{2}$, $\mathrm{u}$ : is the coseismic slip which is calculated using the $4-10$ scaling laws or is taken from previous studies, $\mathrm{L}$ : is the length of the fault that can be derived from equations 4-10 or from previous investigations, w: is the width of the fault and is calculated from the scaling laws 4-10. A second way to calculate the width of the fault is from the seismogenic layer and the faults dip. From studies of aftershock sequences and local experiments, where the hypocenter location is of better accuracy than the regional data, it is derived that the majority of the foci have focal depths of 3 to $15 \mathrm{~km}$. Considering this information the seismogenic layer in our calculations for the fault width is taken to be in the range of 3 to $15 \mathrm{~km}$ for all the strong (M $\geq 6.5$ ) earthquakes that are included in our model.

\section{- Faults associated with coseismic dislocations:}

- Faulting Type (strike slip, normal, thrust)

- Fault parameters (location, length, width and coseismic slip). The values of these parameters are taken from previous studies or were estimated from the equations 4-10 as it was already mentioned.

- Parameters that are needed for the calculation of the static stress. These parameters are used as an input for Dis3d dislocation program. The input file must specify the coordinates of the "observation points" which are the points at which the elastic fields are to be calculated $\left(\mathrm{x}_{1}{ }^{\mathrm{G}}\right.$ : the distance measured at the $\mathrm{x}_{1}{ }^{\mathrm{G}}$ axis (horizontal axis in the $\mathrm{N}$ $\mathrm{S}$ direction), $\mathrm{x}_{2}{ }^{\mathrm{G}}$ : the distance measured along the $\mathrm{x}_{2}{ }^{\mathrm{G}}$ axis (horizontal axis in the E-W direction) and the parameters needed to describe the dislocation plane in the model which are: the dislocation plane's identification number, the half length of the dislocation plane, the distance measured down-dip from the local coordinate origin to the upper (and lower) edge of the dislocation plane, the dip and strike of the fault and the amounts of strike-slip and dip-slip motion in the dislocation plane. In addition the database contains the parameters needed for the grid of observation coordinates and the dip and strike of the target fault according to which the stress changes will be calculated.

An example of the above calculation is depicted if Figure 3. Some of the parameters that were described are appeared here. The column 'Method_ID' denotes the source catalogue for the data. This gives the user the ability to perform comparisons of the results for the same earthquake using different sources. All the geometrical parameters can be added here. For example the column 'Length' is the length of the fault from previous investigation and the column 'Calc_length' is the fault length that is calculated from scaling laws. Here the user can also add or delete a record.

\subsubsection{Parameters of major active faults associated with stress changes}

This application comprises a useful tool for the calculation of the static stress changes and the evolution of the stress field. The information that must be provided from the user is the following:

- The geometry of major faults on which the tectonic loading takes place and the slip rates on them must be defined for the calculation of the cumulative changes in stress. The information on the geometry is taken from previous relevant studies (e.g Bozkurt 2001, Papazachos et al. 2001). The slip rates on specific fault segments are taken from measurements based on Global Positioning System (GPS) (e.g. Reilinger et al. 2006).

- $\triangle \mathrm{CFF}$ is calculated for a specific faulting type (strike slip, normal, thrust) that of the next inspected event. Therefore, information on the fault plane solutions of each strong earthquake is needed that is taken from previous investigations and is included in the database along with rupture dimensions and the coseismic slip. 


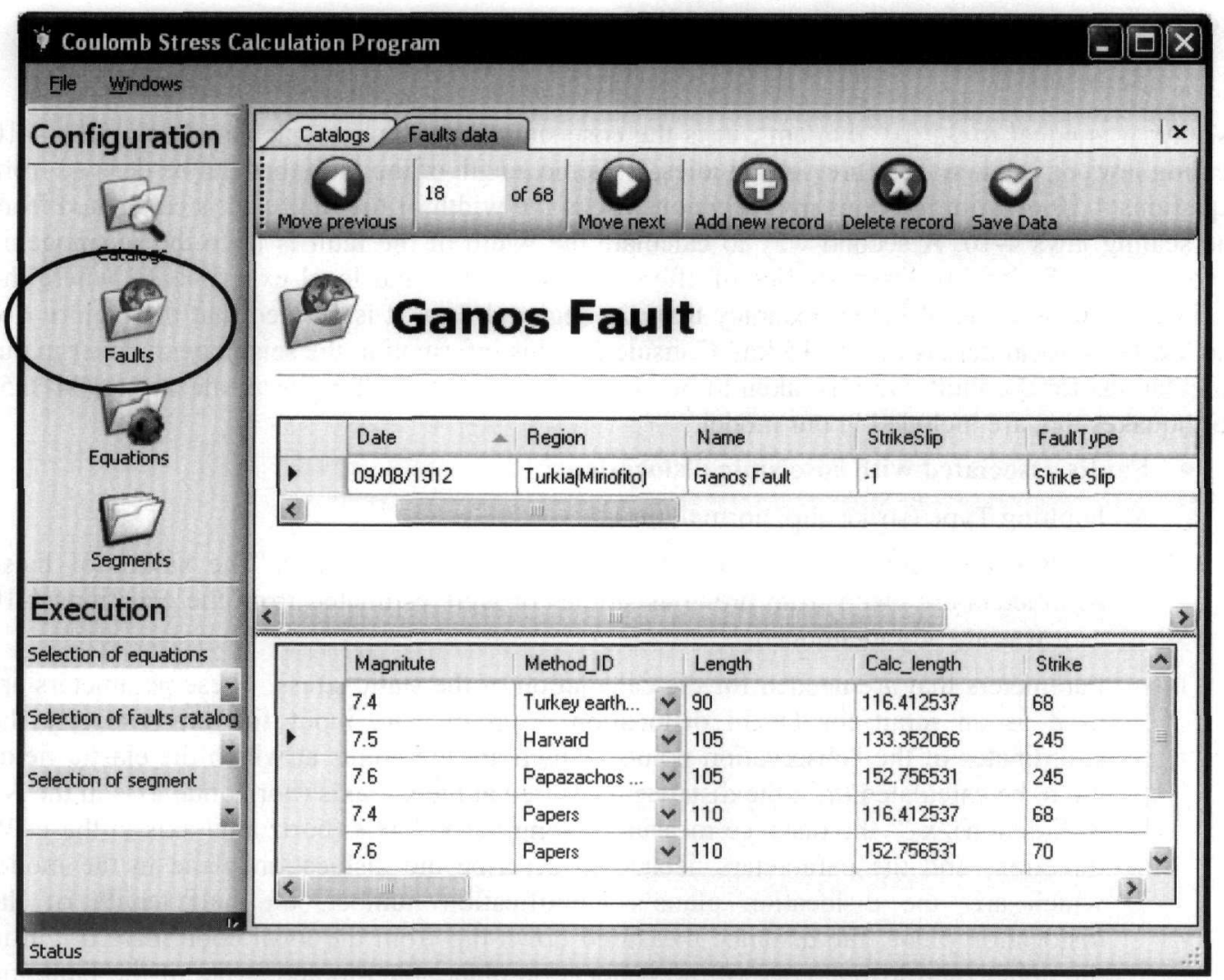

Figure 3 - Screenshot that shows the necessary source parameters of the faults in the study area and the information used for the earthquakes

\subsubsection{Equations tool}

In equations table the scaling laws used for the calculation of faults parameters are illustrated. Figure 4 is a screenshot of the equations used for each type of fault and their source (Papazachos et al. 2004 or Wells and Coppersmith 1994 equations). The user can add or delete as many equations as necessary. All the results are transferred directly and automatically in the database.

\subsection{Execution of Calculations}

\subsubsection{Morphology maps}

For the determination of the parameters of the faults, studies of seismic sequences, field observation of surface traces and morphology maps are used. The morphology of an area provides a useful tool for constraining the fault location which is important input parameter for the spatial distribution of static stress changes The application plots morphology maps if the *.grd files for the specific regions are provided as input file to the GMT program.

\subsubsection{Coulomb Stress Calculations}

In order to perform static stress changes calculations the catalogue that contains the earthquakes to be included in the stress evolutionary model is selected, as well as the set of equations that will be applied. The next step is to select whether the procedure will continue by using the default data (e.g. length) from previous studies or the values that were calculated based on the selected equations. Finally the user can execute all the necessary programs (dis3dop.exe, title etc.) and scripts to get the final plot of the spatial distribution of stress changes (Fig. 5). 


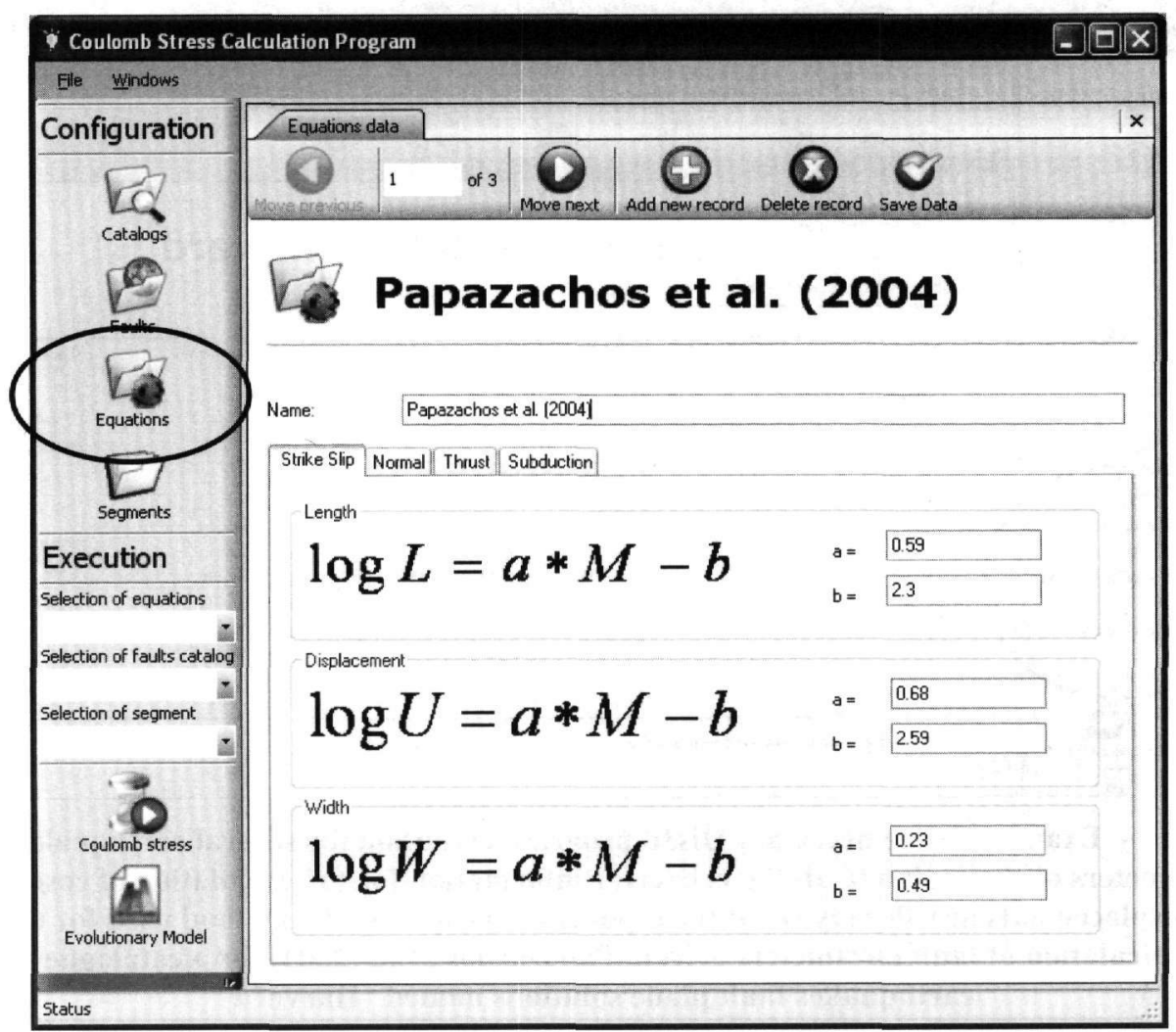

Figure 4 - Example of the use of the scaling laws for the calculations of fault parameters

An example of the application is given here concerning the estimation of both the coseismic stress changes and the evolution of the stress field since the beginning of the $20^{\text {th }}$ century in the territory of western Turkey, in an attempt to testify if the history of cumulative changes in stress can explain the spatial and temporal occurrence patterns of strong earthquakes in this area. The coseismic stress changes as well as the tectonic loading are combined and calculated by the use of this tool. Previous investigations using the Coulomb stress technique have been performed for this area (Stein et al. 1994, Nalbant et al. 1998, Papadimitriou and Sykes 2002) but their models differs from ours in that either do not include tectonic loading or are referred in smaller area and shorter period. In addition the difference from previous studies is that in our study the stress change calculations are carried out for both strike-slip and normal faulting.

\subsection{Examination of the results}

After the execution of one of the above described procedures, the user has the ability to examine the results by viewing or printing them (maps or data files).

\section{Conclusions}

The main advantages of the Coulomb Stress Application are: a) provision of a friendly way to collect and store information concerning the faults and earthquakes of a certain area, b) provision of a standardized fast and efficient way to perform a series of estimations [e.g. fault length (L), fault width (w), coseimic slip (u)], c) significant reduction of the risk for an erroneous calculation, which is avoided thanks to the automated and tested procedure, d) provision of an interactive environment such that the user at any stage is able to check the procedure step by step and to control the input files from the tables and the results and e) allowance with an easy way to enter or to delete data such as earthquake groups, parameters of earthquakes and faults or scaling laws. 


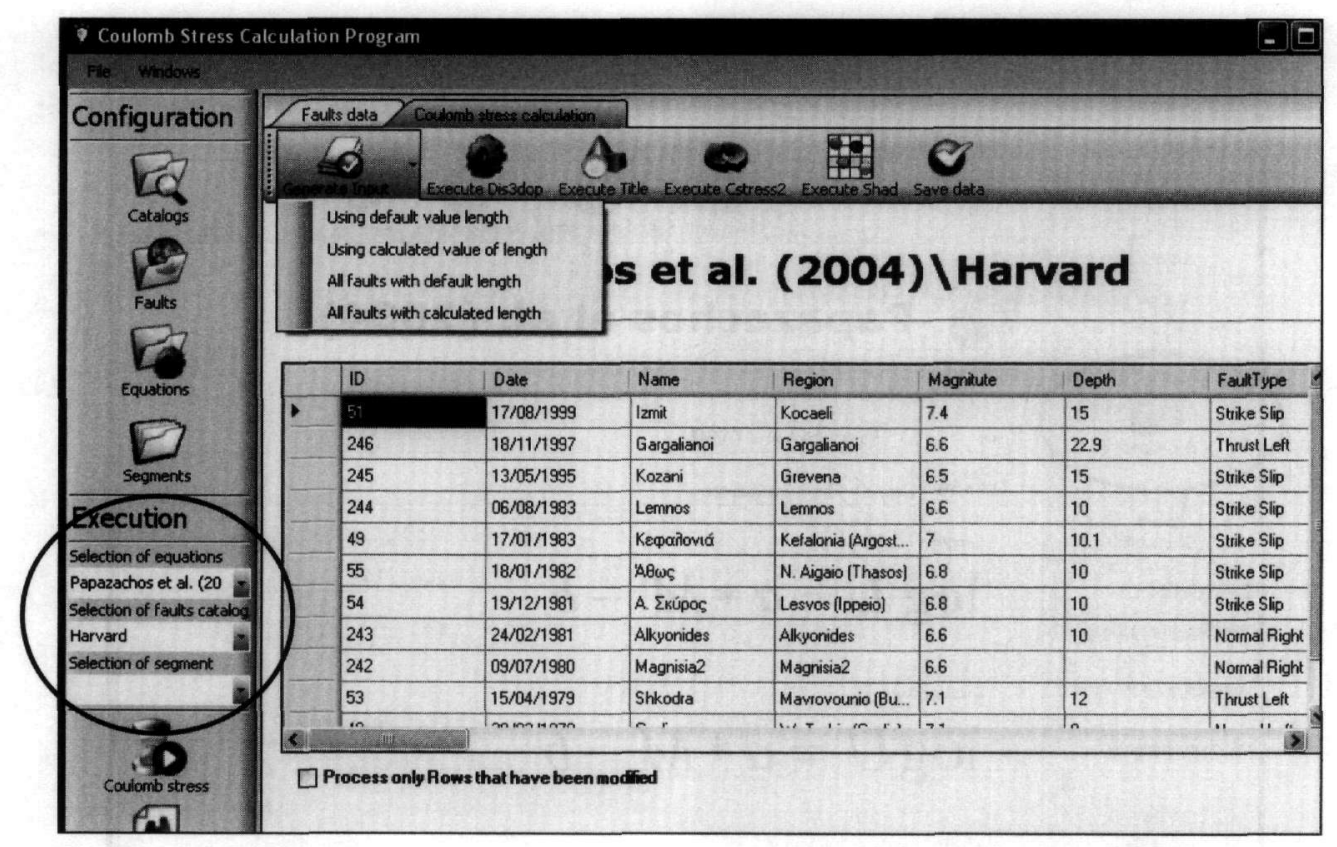

Figure 5 - Example of the necessary Dis3d program execution for several earthquakes. The parameters of the fault and all the necessary information for the calculation of coseismic displacements are already set at the input file. In this case the method used for the calculation of fault parameters is from Papazachos et al. (2004) for a catalogue of earthquakes fault plane solutions named "Harvard"

\section{Acknowledgments}

The manuscript benefited from the review of an anonymous reviewer.

The authors wish to express their sincere and profound thanks to Spyrou George for many useful suggestions and ideas to prepare this application. The first of the authors is a grantee of PENED project funded by the General Secretariat of Research \& Technology of Greece (Grant no. 03E $\Delta 81561585$ 23-09-05). This is Geophysics Department contribution 692.

\section{References}

Aki, K., 1966. Generation and propagation of G-waves from the Niigata earthquake of June 16, 1964. 2. Estimation of earthquake movement, released energy and stress-strain drop from G spectrum, Bull. Earthq. Res. Inst., 44, 23-88.

Bozkurt, E., 2001. Neotectonics of Turkey - a synthesis, Geodinamica Acta, 14, 3-30.

Deng, J., and Sykes, L.R., 1997. Evolution of the stress field in Southern California and triggering of moderate-size earthquakes: A 200-year perspective, J. Geophys. Res., 102, 9859-9886.

Erickson, L., 1986. User's Manual For DIS3D: A Three-Dimensional Dislocation Program With Applications To Faulting In The Earth, M.S. Thesis, University of Stanford, Stanford, California, $167 \mathrm{pp}$.

Haris, R.A., 1998. Introduction to special section: Stress triggers, stress shadows, and implications for seismic hazard, J. Geophys. Res., 103, 24, 347-24, 358. 
Jaumé, S.C., and Sykes, L.R., 1996. Evolution of moderate seismicity in the San Francisco Bay region, 1850-1993: Seismicity changes related to the occurrence of large and great earthquakes, J. Geophys. Res., 101, 765-789.

King, G.C.P., Stein, R.S., and Lin, J., 1994. Static Stress changes and the triggering of earthquakes, Bull. Seism. Soc. Am., 84, 935-953.

Nalbant, S.S., Hubert, A., and King, G.C.P., 1998. Stress coupling between earthquakes in Northwestern Turkey and the North Aegean Sea, J. Geophys. Res., 103, 24, 469-24,486.

Papadimitriou, E.E., and Sykes, L.R., 2001. Evolution of the stress field in the northern Aegean area (Greece), Geophys. J. Int., 46, 747-759.

Papadimitriou, E.E., Xueze Wen, Karakostas, V.G., and Xueshen Jin, 2004. Earthquake triggering along the Xianshuihe fault zone of western Sichuan, China, Pure Appl. Geophys., 161, $1683-1707$.

Papazachos, B.C., 1989. Measures of earthquake size in Greece and surrounding areas, Proc. $1^{s t}$ Scient. Cong., Geophys. Soc. Greece, Athens, April 19-21, 438-447.

Papazachos, B.C., Mountrakis, D.M., Papazachos, C.B., Tranos, M.D., Karakaisis, G.F., and Savvaidis, A.S., 2001. The faults that caused the known strong earthquakes in Greece and surrounding areas during $5^{\text {th }}$ century B. C. up to present, $2^{\text {nd }}$ Conf. Earthq. Engin. Seism., 2830 September, Thessaloniki, 1, 17-26.

Papazachos, B.C., Scordilis, E.M., Panagiotopoulos, D.G., Papazachos, C.B., and Karakaisis, G.F., 2004. Global Relations between seismic fault parameters and moment magnitude of Earthquakes, Bull. Geol. Soc. Greece, XXXVI, 1482-1489.

Reasenberg, P.A., and Simpson, R.W., 1992. Response of regional seismicity to the static stress change produced by the Loma Prieta earthquake, Science, 255, 1687-1690.

Reilinger, R., McClusky, S., Vernant, P., Lawrence, S., Ergintav, S., Cakmak, R., Ozener, H., Kadirov, F., Guliev, I., Stepanyan, R., Nadariya, M., Hahubia, G., Mahmoud, S., Sakr, K., ArRajehi, A., Paradissis, D., Al-Aydrus, A., Prilepin, M., Guseva, T., Evren, E., Dmitrotsa, A., Filikov, S.V., Gomez, F., Al-Ghazzi R., and Karam, G., 2006. GPS constraints on continental deformation in the Africa-Arabia-Eurasia continental collision zone and implications for the dynamics of plate interactions, J. Geophys. Res. 111, doi: $10.1029 / 2005 J B 004051$.

Scholz, C., 1990. The mechanics of earthquakes and faulting, Cambridge University Press, 139pp.

Stein, R.S., Barka, A.A., and Dieterich, J.H., 1994. Progressive failure on the North Anatolian faul t since 1939 by earthquakes stress triggering, Geophys. J. Int., 128, 594-604.

Steketee, J.A., 1958. On Volterra's dislocations in a semi-infinite elastic medium, Can. J. Phys., 36, 192-205.

Toda, S, Stein, R.S.,Lin, J., and Selvigen, V., 2007. Coulomb 3.0, Graphic rich dislocation software for displacements and stress calculations, USGS, Earthquake Hazards Programs, URL.http://quake.wr.usgs.gov/research/deformation/modeling/coulomb/download/index.ht $\mathrm{ml}$

Wells, D.L., and Coppersmith, K.J., 1994. New empirical Relationships among Magnitude, Rupture Length, Rupture width, Rupture area, and Surface Displacement, Bull. Seism. Soc. Am., 84, 974-1002.

Wessel, P., and Smith, W.H.F., 1998. New, improved version of the Generic Mapping Tools Released, EOS Trans. $A G U, 79,579$. 